\title{
Pengaruh Komunikasi Pemasaran dan Affiliate Marketing terhadap Volume Penjualan
}

Ana Ramadhayanti

Email : ana.rdx@bsi.ac.id

\begin{abstract}
ABSTRACK
Saat ini penjualan secara online banyak mengalami perkembangan secara pesat. Hal ini terlihat dari beberapa situs internet yang mewarkan berbagai barang atau produk yang disuguhkkan kepada pembeli. Memang tidak mudah dalam menawarkan barang secara online, karena penjualan yang dilakukan secara konvesionel membutuhkan berbagai strategi yang dilakukan. Oleh sebab itu penjulan yang dilkaukan dengan car aonline juga tentunya harus memiliki strategi kuat dar penjualan secara konvensional. Komuniksi pemasaran menjadi hal ynag sangat penting dilakukan dalam menawarkan barang atau jasa dilakukan secara online, mulai dari membujuk, merayu dan mempromosikan barang menjadi suatu hal yang harsu dilakukan secara tepat. Banyak orang yang menjajakan barang dagangan mereka dengan memnafaatkan situs online, yang pada nantinya akan membagikan sistem keuntungan mereka dengan sitem bagi hasil atau istilah pemasarannya adalah affiliate marketing. Pada dasarkan hal tersebut dilakukan agar volume penjualan meningkat. Untuk membuktikan berbagai hal tersebut maka perlu dilakukan penelitian lebih lanjut. Penilitian yang dilakukan dalam hal ini menggunakan metode kuantitatif dengan membagiakan kuesioner kepada para pedagang online. Berdasarkan dari hasil penelitian didaptkan bahwa Komunikasi Pemasaran dan Affiliate Marketing memiliki pengaruh terhadap Volume Penjualan.
\end{abstract}

Kata Kunci: Komunikasi Pemasaran, Affiliate Marketing, Volume Penjualan. 


\section{PENDAHULUAN}

Pemasaran saat ini menjadi peranan yang sangat penting dalam sistem jula beli. Saat ini telah banyak sistem pemasaran baik yang bersifat online maupun secara konvensional. Sistem jual beli yang dilakukan secara online telah banyak dilakukan dimasyarakat terutama dalam bidang perdagangan dengan sistem e-commerce. Sifat yang praktis dan efisien membuat masyarakat banyak yang beralih berdagang dari sistem perdagangan konvensional ke sitem online. Saat ini banyak sekali dijumpai berbagai nama produk online yang telah ada di masayarkat mulai dari bukalapak, tokopedia, shoope, blibi dan lain. Para pedagang menggunakan sitem lapak tersebut untuk menjual sebagala macam produk yang dijual. Sustem seperti dalam pemasaran biasa disebut dengan Affilite Marketing. Namun tentunya meskipun sistem penjualan dilakukan dengan cara online setiap pedagang tentu mengalami kesulitan dan harus ada strategi dalam menjula produk tersebut. Hal ini tentu tidak dapat dilepaskan dengan sistem komunikasi pemasaran. Bahasa yang digunakan dalam menawarkan suatu produk menjadi hal yang penting diperhatikan karena pembeli akan mencari produk yang dijual berdasarkan kata kunci dari judul produk tersebut. Pembuatan judul dalam sistem pemasaran harus diperhatikan agar pembeli tidak mengalami kesulitan untuk menacri produk barang yang diinginkan, yang dalam hal ini balik lagi ke komunikasi pemasaran yang digunakan. Sementara itu contoh lain yang dapat digunakan untuk melakukan sistem komunikasi pemasaran adalah bahasa promosi, membujuk atau merayu pembeli. Seorang penjual harus dapat menyakinkan produk barang yang dijual kepada pembeli dengan komunikasi yang dapat menyakinkan pembeli memilih produk tersebut. Dengan komunikasi pemasaran yang baik akan membuat barang yang dijual akan laku dipasaran, hal ini tentunya tidak lepas dari peran komunikasi pemasaran yang digunakan dilakukan dengan maksimal. Banyak produk yang dijual mengalami kerugian karena barang yang ditawarkan tidak laku dipasaran, yang tentunya hal ini juga tidak terlepas dari komunikasi pemasaran yang dilakukan tidak berjalan dengan baik. Penggunaan bahasa yang digunakan tidak pas membuat pembeli menjadi kurang yakin terhadap produk barang yang dijual tersebut. Jika seorang pedagang yang memasarkan produk tersebut secara online dengan menggunakan komunikasi pemasaran yang digunakan secara tepat guna dan efektif tentu hal ini akan membuat barang yang dijual semakin banyak atau dalam dengan kata lain dapat meningkatkan volumen penjualan akan meningkat. Namun tentunya hal ini semua dapat dilakukan dengan melakukan penelitian lebih lanjut. Oleh sebab itu untuk membuktikan hal ini maka peneliti tertarik untuk melalakukan penelitian ini lebih lanjut dengan judul penelitian " Pengaruh Komunikasi Pemasaran dan Affiliate Marketing terhadap Volume Penjualan “. 


\section{TINJAUAN PUSTAKA}

\section{Komunikasi Pemasaran}

Firmansyah (2020) Komunikasi pemasaran (marketing communication) adalah sarana di mana perusahaan berusaha menginformasikan, membujuk, dan mengingatkan konsumen secara langsung maupun tidak langsung tentang produk dan merek yang dijual. Kata 'Komunikasi Pemasaran' memiliki dua unsur pokok, yaitu: Komunikasi : Proses dimana pemikiran dan pemahaman disampaikan antar individu, atau antar organisasi dengan individu. Komunikasi sebagai proses penyampaian pesan yang merupakan gagasan atau informasi pengirim melalui suatu media kepada penerima agar mampu memahami maksud pengirim. Pemasaran : Sekumpulan kegiatan dimana perusahaan atau organisasi lainnya mentranfer nilai-nilai (pertukaran) tentang informasi produk, jasa dan ide antara mereka dengan pelangganya. Dari dua pengertian kata tersebut dapat kita simpulkan bahwa Komunikasi pemasaran (bahasa Ingrris: marketing communication / marcomm) adalah sarana di mana perusahaan berusaha menginformasikan, membujuk, dan mengingatkan konsumen secara langsung maupun tidak langsung tentang produk dan merek yang dijual. Komunikasi pemasaran mempresentasikan "suara" perusahaan dan mereknya serta merupakan sarana dimana perusahaan dapat membuat dialog dan membangun hubungan dengan konsumen. Komunikasi pemasaran bagi konsumen, dapat memberitahu atau memperlihatkan kepada adalah sesuatu yang mudah. Komunikasi adalah sebuah usaha untuk menyampaiakan pesan positif atau negative dengan maksud tertentu yang dilakukan oleh seseorang kepada orang lain mellaui media yang digunakan. Definisi singkat ini mungkin dapat menggambarkan dengan lebih jelas mengenai apa itu komunikasi. Sementara itu, pemasaran adalah segala usaha yang dilakukan dalam menyediakan barang untuk pasar, mulai dari merumuskan produk hingga mempromosikan produk tersebut kemasyarakat. Dua hal ini walaupun berbeda, akan tetapi sangat berkaitan.

\section{Esensi Komunikasi Dalam Pemasaran}

Panuju (2019) Di baian depan telah dijelaskan, dalam pemasaran tradisional yang masih konvensional, esensi utama dalam pemasaran adalah produk. Hal itu berangkat dari suatu asumsi bahwa dalam siatu pasar yang belum kopetitif, tidak memberikan pilihan bagi konsumen untuk memilih produk sesuuai dengan yang diinginkan. Bagi konsumen situasi pasar seperti itu berlaku pepatah "tak ada gading ritan pun jadilah..." Transaksi masih didasarkan pada pemenuhan kebutuhan semata. Dalam situasi seperti ini, komunikasi belum terlalu dituntut kehadirannya kecuali sekedar menyampaikan maksud menawarkan produk itu sendiri dan konsumen menyetujui atau menolaknya. Meskipun bentuk pasar masih sangat sederhana, komunikasi masih sangat diperlukan untuk memastikan bahwa apa yang dimaksud pemasar (komunikator) sampai pada calon konsumen (komunikan) berkesuaian. Paling tidak pemasar menyampaikan pesan tentan produk dan penawar dengan 
menggunakan bahasa yang dapat dimengerti oleh konsumen. Juga disampaikan dengan cara berbicara yang dapat diterima oleh konsumen, termasuk menggunakan etika (tata karma) yang lazim digunakan dalam interaksi sosial. Tak kalah pentingnya menggunakan bahasa nonverbal (bahasa tubuh) yang tidak asing bagia konsumen. Hal-hal mendasar seperti ini harus dilakukan oleh komunikator bila tujuan pemasarannya ingin berhasil. Karena itu, menurut Neni Yulianita dalam (Panuju, 2019) peran komunikasi pemasaran dari tahun ke tahun menjadi semakin penting dan memerlukan pemikiran ekstra dalam rangka memperkenalkan, menginfirmasikan, menawarkan, memengaruhi, dan mempertahankan tingkah laku pembeli dari konsumen dan pelanggan potensial suatu perusahaan.

\section{Volume Penjualan}

Rangkuti (2009) Penjualan meruapakan tujuan utama dilakukannya kegiatan perusahaan. perusahaan dalam menghasilkan barang/jasa mempunyai tujuan akhir, yaitu untuk menjual barang/jasa tersebut kepada masyarakat. Oleh karena itu, penjualan memegang peranan penting bagi perusahaan agar produk yang dihasilkan oleh perusahaan dapat terjual dan memberikan penghasilan bagi perusahaan. Penjualan yang dilakukan perusahaan bertujuan untuk menjual barang/jasa yang diperlukan sebagai sumber pendapatan untuk menutup semua ongkos untuk memperoleh laba. Penjualan adalah pemindahan hak miliki atas barang atau pemberian jasa yang dilakukan penjualan kepada pembeli dengan harga yang disepakati bersama dengan jumlah yang dibebankan kepada pelanggan dalam penjualan barang/jasa dalam suatu periode akutansi. Volume penjualan adalah pencapaian penjualan yang dinyatakan secara kuantitatif dari segi fisik atau volume atau unit suatu produk. Volume penjualan merupakan sesuatu yang menandakan naik turunya penjualan dan dapat dinyatakan dalam bentuk unit, kilo, ton atau liter.

Volume penjualan merupakan jumlah total yang dihasilkan dari kegiatan penjualan barang. Semakin besar jumlah penjualan yang dihasilkan perusahaan, maka besar kemungkinan laba yang akan dihasilkan perusahaan. Oleh karena itu, volume penjulanan merupakan salah satu hal penting yang harus dievaluasi untuk memungkinkan perusahaan agar tidak rugi. Jadi volume penjualan yang menguntungkan harus menjadi tujuan utama perusahaan dan bukannya untuk kepentingan volume itu sendiri.

\section{Affiliate Marketing}

Helianthusonfri (2014) Affiliate marketing bisa kita artikan sebagai pemasaran afiliasi, yang artinya adalah kita akan memasarkan produk orang lain. Lalu kemudian kalau kita berhasil menjual produk tadi, maka kita akan mendapatkan komisi dari si pemiliki produk. Ambil contoh si A jual rumah, nah Anda membantu mencarikan pembeli untuk si A tadi. Lalu datang si C, si C ini mau beli rumah. Lalu, Anda arahkanlah si $\mathrm{C}$ tadi dengan si $\mathrm{A}$. Akhirnya si A berhasil menjual rumah kepada si $\mathrm{C}$ karena upaya Anda. Nah, si A akan memberikan komisi kepada Anda. 
Agar kita bisa menjalankan kegiatan menghasilkan uang di internet dengan affiliate marketing (pemasaran afiliasi), maka kita perlu bekerja sama dengan penyedia layanan afiliasi. Di internet, ada banyak situs penyedia layanan afiliasi, mulai dari yang lokal Indonesia sampai yang dari luar negeri. Contohnya seperti: Clickbank.com, Amazon.com, Jvzoo.com.

\section{Kelebihan Menjalankan Affiliate Marketing}

Affiliate Marketing punya sejumlah kelebihan untuk dijalankan oleh kita yang baru mulai atau baru mau terjun ke bisnis online. Inilah beberapa kebihan dari program penghasilan online affiliate marketing: Relatif lebih cepat. Lebih cepat dalam arti untuk memulainya bisa sekarang juga. Anda tidak harus repot-repot membuat produk dulu, Anda tinggal memasarkan produk dari orang lain. Modal relative lebih murah. Dengan affiliate markrting, ada biaya-biaya yang tidak perlu Anda kelaurkan, seperti Anda tidak harus membuat website penawaran produk, tidak harus memikirkan biaya pengelolaan pelanggan atau biaya-biaya lainnya. Risiko kerugian jauh lebih kecil. Ada banyak biaya yang bisa kita minimalisilir, sehingga risiko kerugian bisa diperkecil.

\section{METODE PENELITIAN}

Penelitian ini menggunakan metode penelitian kuntitatif dengan cara membagikan kuesioner kepada para penjual online. Cara pengambilan sampel dalam penelitian ini menggunakan rumus slovin, yang didaptkan jumlah sampel sebanyak 400 orang.

\section{KERANGKA KONSEP PENELITIAN}

Kerangka konseptual model dalam penelitian ini disusun berdasarkan kajian teoritis maupun empiris adalah sebagai berikut :

Gambar 1, Kerangka Konseptual Model Penelitian

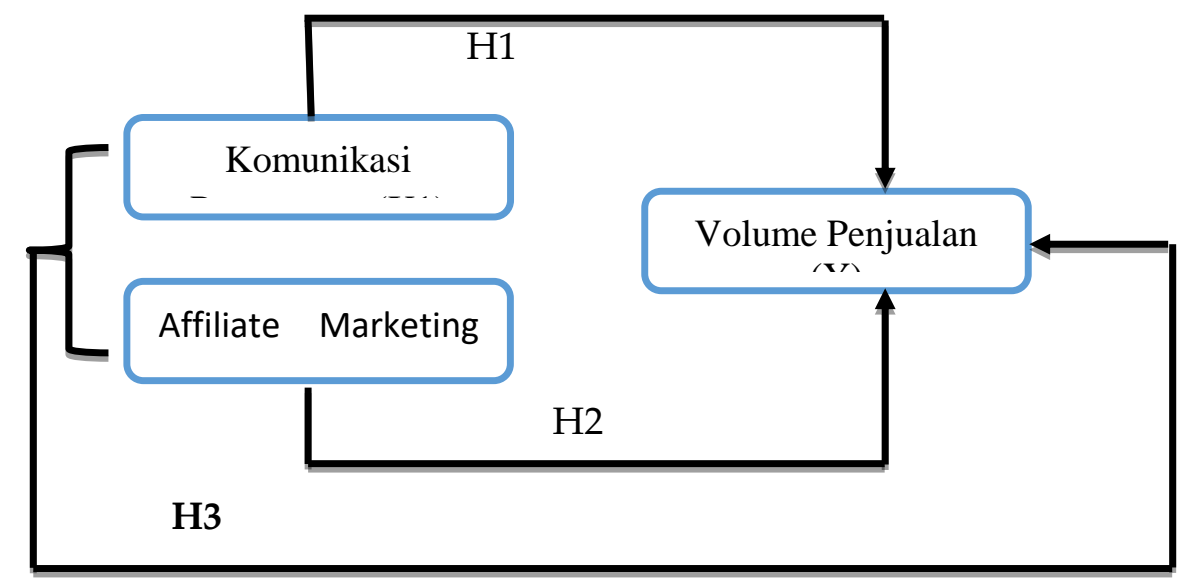

\section{HIPOTESIS PENELITIAN}


Azuar, Irfan (2014) Hipotesis adalah dugaan atau jawaban sementara dari pertanyaan yang ada pada perumusan masalah penelitian. Dikatakan jawaban sementara oleh karena jawaban yang ada adalah jawaban yang berasal dari teori.

Berdasarkan pada kerangka konseptual model penelitia tersebut di atas, maka dapat disusun suatu hipotesis penelitian sebagai berikut:

H1 : Terdapat Pengaruh Komunikasi Pemasaran terhadap Volume Penjualan

H2 : Terdapat Pengaruh Affiliate Marketing terhadap Volume Penjualan

H3 : Terdapat Pengaruh Komunikasi Pemasaran dan Affiliate Marketing terhadap Volume Penjualan.

\section{HASIL PENELITIAN DAN PEMBAHASAN}

\section{Uji Validitas dan Reliabilitas}

\section{Validitas}

Azuar, Irfan (2014) Apabila menggunakan SPSS maka kriteria menarik kesimpulan untuk menentukan valid tidaknya suatu instrument adalah dengan melihat probabilitas kesalahan dari korelasi (disimbolkan dengan Sig). Nilai kesalahan (Sig) hasil dari perhitungan SPSS tersebut dibandingkan dengan probabilitas kesalahan yang ditetapkan oleh peneliti yang disimbolkan dengan alpha $(\alpha)$. Umumnya dalam penelitian sosial nilai $\alpha$ yang dipilih adalah 0,05 . Jika nilai Sig $<\alpha 0,05$, maka suatu item istrumen yang diuji korelasinya adalah valid.

Berdasarkan dari hasil perhitungan menujukkan bahwa baik variabel Komunikasi Pemasaran (X1), Affiliate Marketing (X2) dan Volume Penjualan (Y) memiliki nilai Sig kurang drai 0,05, Sig <0,05. Maka dengan demikian dapat simpulkan bahwa semua item yang telah diuji dinyatakan valid.

Selanjutnya, Azuar, Irfan (2014) Nilai koefisien realibiitas (Cronbach's Aplha) memiliki nilai lebih besar dari 0,6 sehingga kesimpulannya adalah istrumen meruapakan instrument yang reliabel. Berdasarkan dari hasil perhitungan maka dapat dinyatakan bahwa semua uji realibilitas baik Komunikasi Pemasaran (X1), Affiliate Marketing (X2) dan Volume Penjualan (Y) dinyatakan reliabel hal ini terlihat dari hasil nilai Cronbach's Aplha diatas 0,6.

\section{Uji Asumsi Klasik}

\section{Uji Normalitas}

Pengujian normalitas data dilakukan untuk melihat apakah dalam model regeresi, variabel dependen dan independennya memiliki distribusi normal atau tidak. Menurut Gujarati, Santoso, arief dalam (Azuar, Irfan, 2014) Jika data menyebar di sekitar garis diagonal dan mengikuti arah garis diagonal maka model regresi memenuhi asumsi normalitas. Hasil uji normalitas menujukkan bahwa data 
hasil perhitungan berada disekitar garis diagonal atau dengan kata lain memperlihatkan bahwa memenuhi asumsi normalitas.

\section{UJi Heteroskedasitisitas}

Heterokedastisitas digunakan untuk menguji apakah dalam model regeresi terjadi ketidaksamaan varians dari residual dari suatu pengamatan yang lain. Jika variasi residual dari satu pengamatan ke pengamatan yang lain tetap, maka disebut homokedastisitas dan jika varians berbeda disebut heterokedsatisitas. Menurut Gujarati, arief, dalam Azuar, Irfan, Manurung 2014 model yang baik adalah tidak terjadi heterokedsatisitas.



Gambar 3 . Normal P-P Plot

Gambar di atas memperlihatkan titik-titik menyebar secara acak, tidak membentuk pola yang jelas teratur, serta tersebar baik di atas maupun di bawah angka 0 pada sumbu Y. Dengan demikian 'tidak terjadi heterokedastisitas' pada model regresi.

\section{Autokorelasi}

Autokorelasi bertujuan untuk menguji apakah dalam sebuah model regresi linear ada korelasi antara kesalahan pengganggu pada periode ke $t$ dengan kesalahan pada periode t-1 (sebelumnya). Jika terjadi korelasi, maka dinamakan aada problem autokorelasi. Model regresi yang baik adalah bebas dari autokorelasi. Salah satu cara mengindentifikasi adalah dengan melihat nilai Durbin Watson (D-W). Jika nilai D-W di bawah -2 berarti ada autokorelasi positif. Jika nilai D-W diantara -2 sampai +2 berarti tidak ada autokorelasi. Jika nilai $\mathrm{D}-\mathrm{W}$ di atas +2 berarti ada autokorelasi negatif. Dari 
nilai pengujian stratistik terlihat bahwa nilai Durbin Watson adalah 1, 934 Dengan demikian tidak terjadi autokorelasi di dalam model regresi.

\section{Uji Multikolinearitas}

Menurut (Trigunawan, Ajis. Rahayu, Woro Isti, Andarsyah, 2020) Tujuan digunakannnya uji multikolinearitas adalah untuk menguji apakah model regresi ditemukan adanya korelasi antar variable bebas atau variable independent. Model regresi yang baik seharusnya tidak terjadi gejala multokolinearitas.

Berdasarkan analisis stratistik pada table ouput 'coefficeints' pada bagian 'collinearity sattistics' diketahui nilai tolerance untuk variable Komunikasi Pemasaran (X1) dan Affiliate Marketing (X2) adalah 0,196 lebih besar dari 0,10. Sementara, nilai VIF untuk variable Komunikasi Pemasaran (X1) dan Affiliate Marketing (X2) adalah 5.092, maka mengacu pada dasar pengambilan keputusan dalam uji multikolinearias dapat disimpulkan bahwa tidak terjadi gejala multikolinearitas dalam model regresi.

\section{HASIL ANALISIS REGRESI LINEAR BERGANDA}

\section{Hasil Uji F}

\begin{tabular}{|c|c|c|c|c|c|c|}
\hline \multicolumn{7}{|c|}{ ANOVA $^{a}$} \\
\hline \multicolumn{2}{|c|}{ Model } & $\begin{array}{l}\text { Sum of } \\
\text { Squares }\end{array}$ & df & $\begin{array}{l}\text { Mean } \\
\text { Square }\end{array}$ & $\mathrm{F}$ & Sig. \\
\hline \multirow[t]{3}{*}{1} & Regression & 16696,497 & 2 & 8348,249 & 4383,106 &, $000^{\mathrm{b}}$ \\
\hline & Residual & 756,143 & 397 & 1,905 & & \\
\hline & Total & 17452,640 & 399 & & & \\
\hline
\end{tabular}

a. Dependent Variable: Volume Penjualan

b. Predictors: (Constant), Komunikasi Pemasaran (X1) , Affiliate Marketing (X2)

Hartono (2018) Pengujian Hipotesis secara simu;tan (uji statistik F) uji F digunakan untuk menguji apakah variabel independen secara bersama-sama mempengaruhi variabel dependen.

Dasar pengabilan keputusan dalam uji $\mathrm{F}$ berdasarkan nilai $\mathrm{F}$ hitung dan $\mathrm{F}$ tabel.

a. Jika nilai $\mathrm{F}$ hitung $>\mathrm{F}$ tabel maka variabel indenden secara simultan berpengaruh terhadap variabel dependen.

b. Jika nilai $\mathrm{F}$ hitung $<\mathrm{F}$ tabel maka vaeiabel independen secara simultan tidak berpengaruh terhadap variabel dependen.

Hasil perhitungan memperlihatkan nilai f hitung 4383,106 > f tabel 3,01 sehingga dapat disimpulkan Komunikasi Pemasaran dan Affiliate Marketing (X2) secara simultan atau bersama-sama berpengaruh terhadap Volume Penjulan. 
Dasar pengambilan keputusan dalam uji $\mathrm{F}$ berdasarkan nilai signifikansi.

a. Jika nilai signifikansi < 0,05 maka variabel independen secara bersama-sama berpengaruh signifikan terhadap varaibel dependen.

b. Jika nilai signifikansi $>0,05$ maka varaibel independen secara bersama-sama tidak berpengaruh signifikan terhadap variabel dependen.

Sementara itu jika dilihat dari nilai signifikansi memperlihatkan Sig. 0,00<0,05 sehingga dapat disimpullkan Komunikasi Pemasaran dan Affiliate Marketing (X2) secara simultan atau bersama-sama berpengaruh terhadap Volume Penjulan.

\section{Uji Regresi}

Dari output SPSS model summary, beserta adjusted $\mathrm{R}$ adalah 0,956; Menurut (Riyanto, Slamet dan Hatmawan, 2020) hal ini menujukkan bahwa $95.6 \%$ variasi variabel Volume Penjualan dapat dijelaskan oleh variasi dari variabel independen (Komunikasi Pemasaran dan Affiliate Marketing). Sedangkan sisanya (100\%-95,6\%) dijelaskan oleh sebab-sebab yang lain di luar model yang diteliti. Untuk nilai Standard Error of the Estimate (SEE) sebesar 1.380 kali, menujukkan bahwa semakin kecil nilai SEE akan membuat model regresi semakin tepat dalam memprediksi variabel dependen.

\begin{tabular}{ll|r|r|r|r} 
& & \multicolumn{4}{c}{ Model Summary $^{\mathbf{b}}$} \\
Model & $\mathrm{R}$ & R Square & $\begin{array}{c}\text { Adjusted R } \\
\text { Square }\end{array}$ & $\begin{array}{c}\text { Std. Error of } \\
\text { the Estimate }\end{array}$ & $\begin{array}{c}\text { Durbin- } \\
\text { Watson }\end{array}$ \\
\hline 1 &, $978^{\mathrm{a}}$ &, 957 &, 956 & 1,380 & 1,934 \\
\hline
\end{tabular}

a. Predictors: (Constant), Komunikasi Pemasaran (X1), Affiliate

Marketing (X2)

b. Dependent Variable: Volume Penjualan

Sumber: Data yang diolah dengan SPSS 25 (2019)

\section{Hasil Uji t}

\begin{tabular}{|c|c|c|c|c|c|c|c|c|}
\hline \multicolumn{9}{|c|}{ Coefficients $^{a}$} \\
\hline & & \multicolumn{2}{|c|}{$\begin{array}{l}\text { Unstandardized } \\
\text { Coefficients }\end{array}$} & \multirow[t]{2}{*}{$\begin{array}{l}\text { Standard } \\
\text { ized } \\
\text { Coefficie } \\
\text { nts }\end{array}$} & \multirow[b]{2}{*}{ 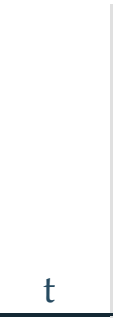 } & \multirow[b]{2}{*}{ Sig. } & \multicolumn{2}{|c|}{$\begin{array}{l}\text { Collinearity } \\
\text { Statistics }\end{array}$} \\
\hline \multicolumn{2}{|c|}{ Model } & $\mathrm{B}$ & $\begin{array}{l}\text { Std. } \\
\text { Error }\end{array}$ & & & & $\begin{array}{c}\text { Tolera } \\
\text { nce }\end{array}$ & VIF \\
\hline \multirow[t]{2}{*}{1} & (Constant) & 1,981 & ,516 & & 3,843 & ,000 & & \\
\hline & $\begin{array}{l}\text { Affiliate } \\
\text { Marketing (X2) }\end{array}$ & ,766 & ,023 & ,772 & $\begin{array}{r}32,74 \\
5\end{array}$ & ,000 & 196 & 5,092 \\
\hline
\end{tabular}




\begin{tabular}{ll|l|l|l|l|l|l}
$\begin{array}{l}\text { Komunikasi } \\
\text { Pemasaran }(\mathrm{X} 1)\end{array}$ &, 218 &, 023 &, 224 & 9,518 &, 000 &, 196 & 5,092 \\
\hline
\end{tabular}

a. Dependent Variable: Volume Penjualan

Menurut (Santoso, 2008) menjelaskan dalam uji t dapat dilihat Berdasarkan Probabilitas.

Jika Probabilitas $>0,025$, maka H0 diterima

Jika Probabilitas <0,025, maka H0 ditolak

Uji dilakukan dua sisi sehingg nilai probabilitas $=0,05 / 2=0,025$.

Keputusasn:

Terlihat bahwa pada kolom Sig/significance adalah 0,000, atau probabilitas jauh di bawah 0,025. Maka H0 ditolak, atau koefisien regresi siginifikan, atau Komunikasi pemasaran dan Affiliate berpengaruh secara signifikan terhadap Volume Penjualan.

\section{KESIMPULAN}

Berdasarkan dari hasil penelitian maka didapatkan hasil bahwa nilai $\mathrm{f}$ hitung 4383,106 > f tabel 3,01 sehingga dapat disimpulkan Komunikasi Pemasaran dan Affiliate Marketing (X2) secara simultan atau bersama-sama berpengaruh terhadap Volume Penjulan. Komunikasi Pemasaran dan Affiliate Marketing (X2) secara simultan atau bersama-sama berpengaruh terhadap Volume Penjulan. Sementara itu jika dilihat dari hasil perhitungan menggunakan uji $t$ dari nilai significance maka terlihat Komunikasi pemasaran dan Affiliate berpengaruh secara signifikan terhadap Volume Penjualan.

\section{DAFTAR PUSTAKA}

Azuar, Irfan, M. (2014). Azuar, Irfan, Manurung. Medan: UMSU PRESS.

Firmansyah, M. A. (2020). Komunikasi Pemasaran. Pasuruan: IKAPI.

Hartono. (2018). Konsep Analisisa Laporan Dengan Pendekatan Rasio E SPSS. Yogyakarta: Deepublish.

Helianthusonfri, J. (2014). 1 Juta rupiah pertama Anda dari Affiliate Marketing. Jakarta: PT Elex Media Komputindo.

Panuju, R. (2019). Komunikasi Pemasaran. Jakarta: Kencana.

Rangkuti, F. (2009). Strategi Promosi yang Kreatif dan Analisis Kasus. Jakarta: PT.

Gramedia Pustaka Utama.

Riyanto, Slamet dan Hatmawan, A. A. (2020). Metode Riset Penelitian Kuantitatif

Penelitian di Bidang Manajemen Teknik, Pendidikam dan Eksprerimen. Yogyakarta:

Deepublish.

Santoso, S. (2008). Panduan Lengkap Menguasai SPSS 16. Jakarta: PT Elex Media

Komputindo.

Trigunawan, Ajis. Rahayu, Woro Isti, Andarsyah, R. (2020). Regresi Linier Untuk Prediksi Jumlah Penjualan Terhadap Jumlah Permintaan. Bandung. 
